\title{
Business Typology for Examining the Risk Management Strategy in Relation to the Activities of Higher Education Institutions in the Sultanate of Oman
}

\author{
Ibrahim Rashid Al Shamsi \\ Unversity of Burimi, College of Business, Al Burimi, Sultanate of Oman
}

\begin{abstract}
This work proposed a business administration strategy for risk management in the activities of universities. Comprising description of actions from recognizing real and potential risks. Data set have been collected and configured to analyze and process several university unites based on a set of criteria that have been developed and tested. The application of the proposed solution will enable the HEI for forecasting and quantitative measurement of risks related to university activities. Aimed at preventing the occurrence of education risks through a clear description of procedures and mechanisms of risk management. The developed university criteria's could be used as a standard for institutions to evaluate their risk management system. The proposed approach could improve risk management in education institutions by $24 \%$. The real-world innovation of this work involves theoretical and methodological development of conceptual requirements for improving the management processes at universities, based on the application of risk management methods.
\end{abstract}

Keywords - Risk Management, Higher Education Institution, Cost-Effective component, Risk Logs

DOI: $10.18421 /$ TEM92-40

https://doi.org/10.18421/TEM92-40

Corresponding author: Ibrahim Rashid Al Shamsi, Unversity of Burimi, College of Business, Al Burimi, Sultanate of Oman.

Email: ibrahim.r@uob.edu.om

Received: 14 February 2020.

Revised: 27 April 2020.

Accepted: 04 May 2020.

Published: 27 May 2020.

(c) BY-NC-ND (C) 2020 Dr. Ibrahim Rashid Al Shamsi; published by UIKTEN. This work is licensed under the Creative Commons Attribution-NonCommercial-NoDerivs 4.0 License.

The article is published with Open Access at www.temjournal.com

\section{Introduction}

The proposed typology of risk management has made it possible to justify the possibility of applying the basic principles of corporate risk management in the risk management process of universities. Therefore, this work selects seven university units (University website, Library, Security, R\&R, Research, Strategy and Quality unit) for identifying the level of risk and the priority of risk mitigation. Also, the university criteria's have been developed such as Functionality, Ease of Use, Documentation, Availability, Response Time, Training, Reliability, Reporting, IT support; Figure 1. describes the university units and the developed criteria.

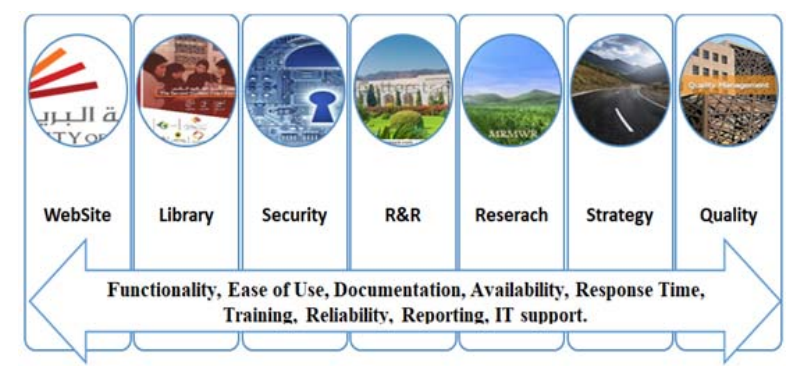

Figure 1. University units and the developed criteria

The Risk Management techniques proposed in the current educational systems are not effective. Most of the Risk Management units in the Higher Education Institution (HEI) are proposed as formal documents for the presentation and as a standard requirement for the institution's accreditation [1]. The current risk management tools are human subjective decisions that define the level of the risk as low, middle and high level respectively. Such a philosophy and strategy to handle and manage the risks in the HEI leads to a big economy loss that could affect the university image and the country's economy. There are many hidden negative gaps (HNG) that could be found in every HEI, such hidden gaps are a great source of treating the HEI performance and its image. Therefore, there is a need for an effective solution to identify the HNG and mitigate such 
negative patterns to improve HEI productivity and reducing risk.

The main properties of risks in higher education institutions (HEI) in Arabic Countries are inconsistency, alternativeness, and uncertainty of situations in which they rise as described in [2]. Such qualities of educational services as intangibility, heterogeneity, inability to store the "productionconsumption" relationship, and thus significantly increase the uncertainty and make it difficult to assess risks in this area. The application of the risk management concept in the activities of universities will contribute to increasing the efficiency of the economic component of the educational process and will improve the quality of decisions. In this case, the basic principles of risk management in the activities of the university are the principles of soundness, manageability, appropriateness and continuity. The significance of the research topic is determined by the fact that in the current conditions of socioeconomic development of the Arabic region, the conditions for the functioning of the educational services market have substantially changed. Risk management in Oman is in its early stages. This is due to the fact that this category has not been considered a theoretical study for a long time, but related only to practice, to the problems of the art of management. The issues of risk management in the activities of non-profit organizations, taking into account the conditions of the modern economy, in particular the Sultanate of Oman. The problem of risk management in the activities of universities in the works of domestic researchers in Oman has not yet been adequately reflected in its contents. When constructing the organizational structure of risk management in a university, it is advisable to use various models, including centralizing risk management at the university as a whole, distributing risk management authorities between functional units, or a combination of both models. In this case, the leading role in the risk management process at the university from the standpoint of the distribution of powers and responsibility should belong to the rector, academic council and financial and economic service of the university, which determines the risk management policy and monitors its compliance. In modern socio-economic conditions, the targeted impact on emerging risk situations in order to minimize their negative consequences, predicting the emergence of new risk situations in the mode of acceptable resource costs, is becoming a necessary condition for universities for their sustainable development. This work is based on the analysis of the activities of educational institutions of higher education to: Identify risk factors affecting the process and the result of their activities, and Develop conceptual scientific and practical recommendations on risk management in higher education institutions for the Sultanate of Oman.

\section{Literature Review}

The effectiveness of the country's economic development largely depends on the state of human resources, professional, technical, economic and scientific training of specialists. In the framework of this direction, the main attention of the current researchers is focused on the study of risk properties such as universality, consistency, inconsistency, and dynamic probability, leading to a change in the constancy stability of the socio-economic system. The quality of public relations and the scale of economic activity increase the uncertainty of processes and contribute to the growth of potential threats to the social and economic stability of society. In this concern, the increasing scale of risks is considered as the most significant characteristic in the framework of these concepts. [3] Considered the higher education as an institution of the national and at the same time as an institution of the economy market, ensuring the continuous establishment of a wide range of educational services to individuals and business entities. Due to the adoption of market principles for the functioning of the economy as a whole, the market of educational services is actively being formed and developed in Oman. The largest and most dynamically developing segment of this market is the system of higher professional education. [4] An analysis of the established practice of the activities of universities allowed this work to consider the university as a holistic unity, which is connected with specific relations with consumers of educational services, society, the public, enterprises, individuals, and at the same time as a social institution with a complex structure, goals and tasks, with diverse internal relations and connections.[1] The study proceeds from the premise that a university, being an element of a higher education system, can itself be considered as a system with specific properties and characteristics necessary. The main systemic features of the university presented in Figure 2.

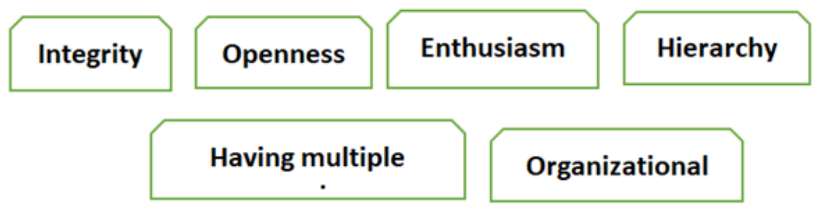

Figure 2. Properties of a university system

One of the main systemic properties of a university is its openness to the external environment. In the conditions of market relations, one of such mechanisms may be the use of risk management methods, the use of which will allow universities to 
improve their activities in an unstable environment and limited resources. [5] Stated that the most noticeable changes were in the increase of the uncertainty in the external environment, increased competition, and a reduction in budget financing of government universities. [6] Previously, sufficient and timely resource support protected government universities from many risks, but now their functioning largely depends on competent and competitive management, which should help to increase the efficiency of their activities and reduce the impact of adverse factors.[7] The governmental classification of a university as a nonprofit organization determines the duality of its position, which consists of the need to satisfy both social (national) and market requirements. [8] In addition, universities were faced with the need to find reserves for their further development, caused by the capacity in some specialties of the market for higher education, the demographic decline, increased competition, expansion and complication of their economic activities, as well as the practically exhausted opportunities and conditions for extensive development.[9] While public universities still have some opportunity to take advantage of the mechanism of budget and extra-budgetary funding, the activities of non-public universities are associated with a greater degree of risk. Even more realizes issues related to risk management in educational institutions, since the strengthening of their independence entails an increase in managerial and especially financial risks for incorrect decisions. In this regard, there is a need to search for effective intra-university risk management mechanisms, to develop scientifically-based areas and specific recommendations adequate to modern conditions of functioning of higher education in Arabic regions. [10],[11] the most important component of a sciencebased risk management concept in universities in the development of a risk management strategy as longterm principles and rules based on forecasting risk situations and using various risk management methods. The conceptual base remains rather controversial, and differences are observed in the approaches to classification and the definition of risk assessment methods.[12],[13] Due to the identified problems, the relevance of the research topic is due to the insufficient development of conceptual problems of risk management in higher education institutions in an economic market.

This work refers to the third group of the concepts defining risks as a form of result uncertainty, which is associated with a special type of economic activity - entrepreneurship. The uncertainty of the conditions in which entrepreneurial activity is carried out is determined by the fact that it depends on many variables, contractors and individuals whose behavior cannot always be predicted with acceptable accuracy. In this regard, the need to study risk, its assessment and regulation arises from the functioning of the market mechanism itself. [14],[15] In the field of higher education, the risk will lie in the possibility (danger) of obtaining an unplanned result due to changes in the educational environment of the university under the influence of external and internal factors. For example, due to insufficient financing of educational activities, the university will not be able to provide the necessary level of quality for theoretical and practical training of their graduates, which will significantly reduce their adaptability in the labor market and lead to a weakening of the university's position in society. However, today there is no generally accepted theoretical approach to the problem of risk management in the field of education, the practical relevance of research related to the application of risk management mechanisms in Arabic domestic universities.

The proposed risk management solution will contribute to the effective use of the existing potential of the university and will allow forecasting risk situations in its activities. Figure 3 . describes the phases of developing the proposed solution in risk management for the HEI.

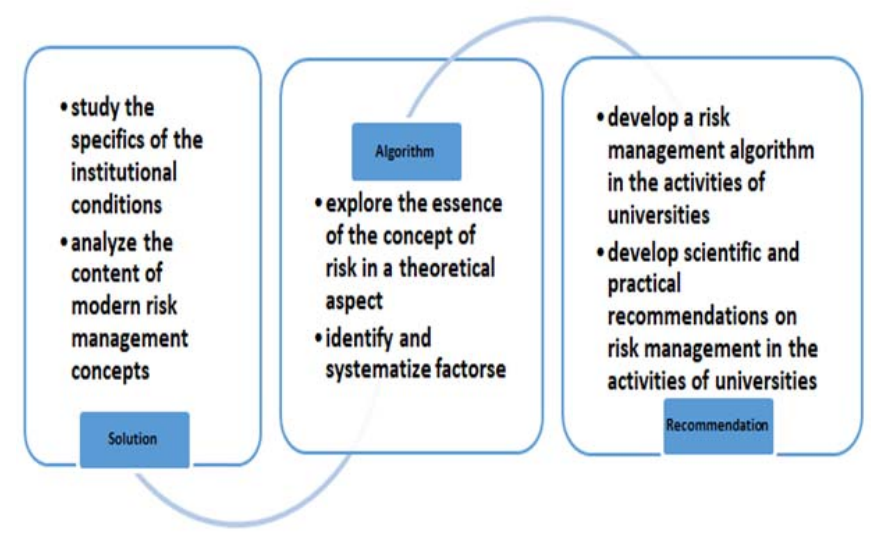

Figure 3. Phases of development the algorithm

This work collected information related to seven university units (University website, Library, Security, R\&R, Research, Strategy and Quality unit), the statistics information from the National Government Statistics Service, authorities, analytical materials from educational projects, publications in periodicals press, the Internet, and assumptions of the author obtained in the course of an expert survey. And with the help of experts developed a set of university criteria including the Functionality, Ease of Use, Documentation, Availability, Response Time, Training, Reliability, Reporting, IT support. Figures 4. and 5. show a sample of the calculated assessment rate related to the university units and developed criteria. 


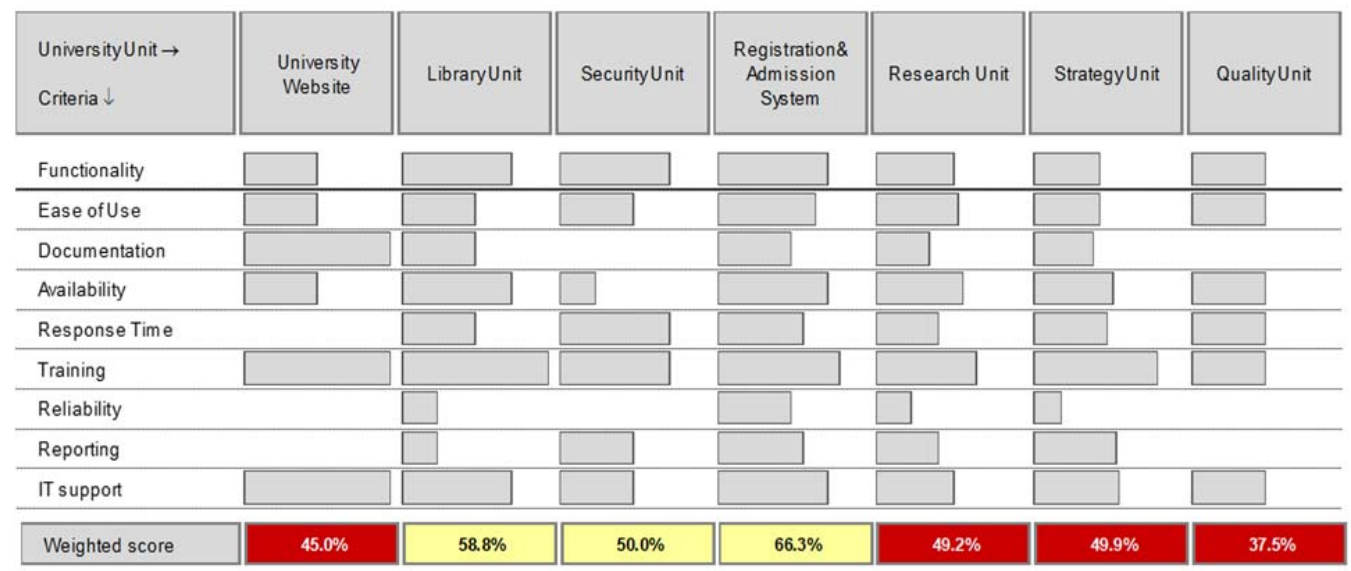

Figure 4. University units and criteria

\section{The Proposed Solution}

The key insights concluded from Figure 4., indicate the weighted score with red color are units that do not meet the expected risk management criteria (not satisfactory).

\begin{tabular}{|c|c|c|c|c|c|c|c|c|}
\hline Fundionality & Ease of Use & $\begin{array}{l}\text { Document- } \\
\text { ation }\end{array}$ & Avaliability & $\begin{array}{c}\text { Response } \\
\text { Time }\end{array}$ & Training & Reliability & Reporting & IT support \\
\hline 1.67 & 1.33 & 1.00 & 1.67 & 1.67 & 1.67 & 1.00 & 1.33 & 1.67 \\
\hline 1.13 & 0.90 & 0.93 & 1.13 & 1.07 & 1.77 & 0.73 & 0.77 & 1.17 \\
\hline 2.00 & 1.50 & 1.50 & 1.50 & 1.25 & 1.75 & 0.50 & 1.50 & 1.25 \\
\hline 1.00 & 1.60 & 120 & 1.60 & 0.60 & 1.20 & 0.20 & 0.80 & 1.00 \\
\hline 2.00 & 1.75 & 1.25 & 2.00 & 1.50 & 2.00 & 0.75 & 1.00 & 2.00 \\
\hline 1.00 & 1.00 & 1.00 & 1.00 & 1.00 & 1.00 & 1.00 & 1.00 & 1.00 \\
\hline 1.33 & 1.00 & 0.67 & 1.33 & 1.33 & 1.00 & 0.33 & 0.67 & 1.67 \\
\hline 1.00 & 1.00 & 0.00 & 1.00 & 1.00 & 1.00 & 0.00 & 0.00 & 0.00 \\
\hline 1.00 & 1.00 & 0.60 & 0.80 & 0.60 & 0.80 & 0.00 & 0.60 & 1.00 \\
\hline 0.50 & 0.50 & 1.00 & 2.00 & 2.00 & 2.00 & 1.50 & 1.00 & 1.50 \\
\hline 1.00 & 1.30 & 1.10 & 1.50 & 0.90 & 1.40 & 0.80 & 0.80 & 0.90 \\
\hline 2.00 & 2.00 & 1.00 & 2.00 & 1.00 & 2.00 & 2.00 & 1.00 & 2.00 \\
\hline 1.56 & 1.22 & 1.33 & 1.67 & 1.11 & 1.89 & 0.11 & 1.33 & 1.44 \\
\hline 1.32 & 1.26 & 0.74 & 1.42 & 1.05 & 1.79 & 0.47 & 1.58 & 1.21 \\
\hline 1.33 & 1.00 & 1.33 & 0.67 & 0.67 & 1.00 & 0.67 & 1.00 & 1.33 \\
\hline 2.00 & 1.33 & 0.67 & 0.67 & 1.67 & 2.00 & 0.67 & 1.00 & 2.00 \\
\hline 0.50 & 0.50 & 0.00 & 0.50 & 1.00 & 0.50 & 0.00 & 1.00 & 1.00 \\
\hline 1.50 & 1.00 & 1.50 & 1.50 & 1.50 & 2.00 & 1.00 & 1.00 & 2.00 \\
\hline
\end{tabular}

In this regard, this work identified the potential risks of the parties interested in the activities of the university and discovered their relationship. Risk management involves

Comprehensive accounting, which in turn requires a classification of risks. The classification of risks developed in this work in the activities of universities as demonstrated in Figure 6., based on the results demonstrated in Figure 4. and 5., the identification of primary and secondary signs of the taxonomy, allows determining the place of each risk in identifying related participants, and to measures the mitigated strategy alongside their negative impact. This work distinguishes the following classification features: by the sphere of occurrence (internal and external), by the severity of the consequences (permissible, critical and catastrophic) and by the nature of possible losses (organizational, financial, personnel, image).

Figure 5. Confused matrix for the developed criteria

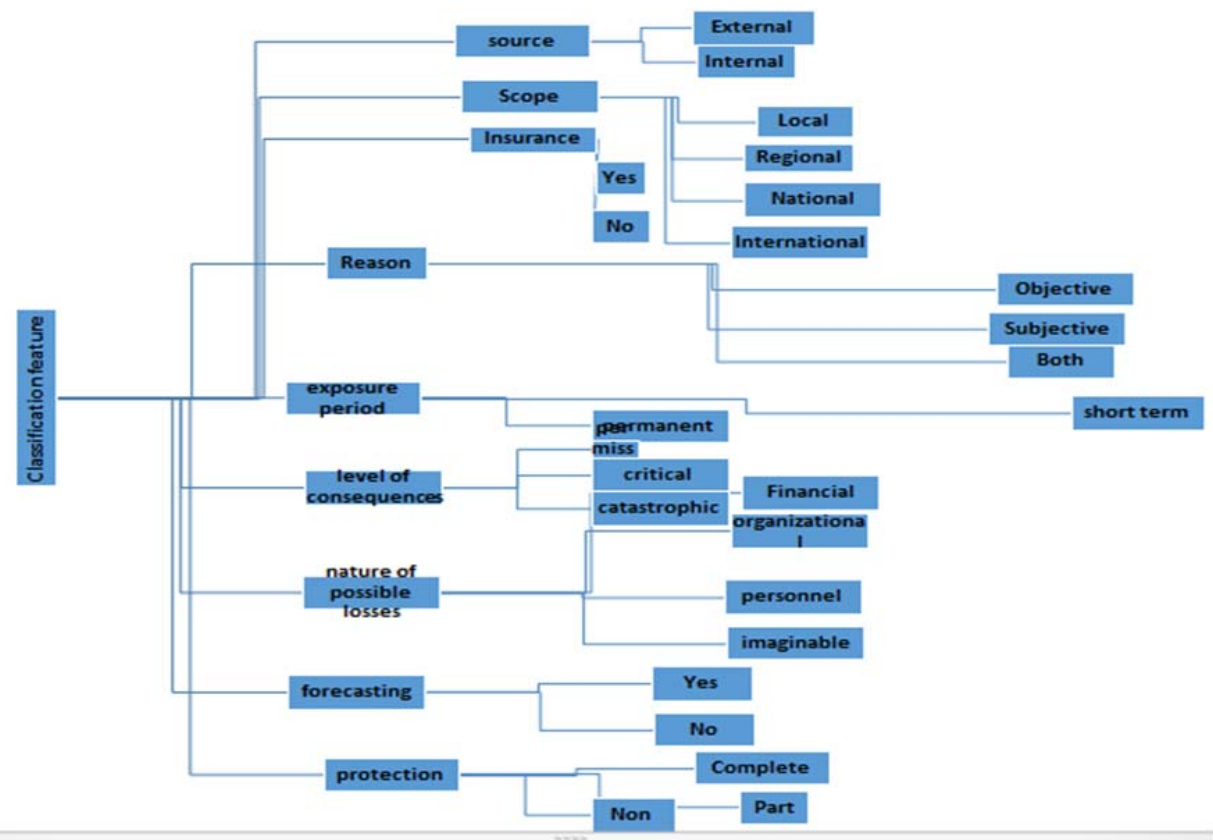

Figure 6. Classification of risks arising in the activities of the university 
Consequently, in the activities of government universities, there are acceptable risks; critical and catastrophic are extremely rare. This is due to the fact that the government universities, based on the principle of subsidiary liability, limit the volume and content of the independent economic activity of government universities, thereby reducing the risk of default and loss. On the other hand, strict regulation of educational activities, compulsory licensing and accreditation of educational programs of universities. For non-government universities, the likelihood of critical risk situations associated with a lack of financial resources, primarily for the development and achievement of strategic and tactical goals, is significantly increased. This work notes that significant differences in the mechanism of financial and economic activities of universities, largely determine the level of losses when risk situations occur and the possibility of applying risk management methods in their activities. The general set of risk-forming factors formed by this work was classified by the sphere of occurrence - on external and internal, by the degree of influence - on direct and indirect. This classification serves as a tool to identify risk factors, establish the necessary relationships taking into account the purpose of the university, the specifics of its activities. In conditions of uncertainty and lack of reliable information about risk situations in the form of frequencies of their manifestation, risk factors can be assessed mainly by expert methods. To achieve the objectives of the study, this work applied an expert survey method implemented by obtaining individual opinions of members of the expert group followed by data processing. The degree of competence of experts is established by the calculated value of the aggregate index-coefficient of the level of competence (formula 1 ), which in the represented group was 0.8792 (with a maximum value of 1.0 ):

$$
\mathrm{Nw}=(\mathrm{nw} 1+\mathrm{nw} 2+\mathrm{nw} 3) / 3
$$

Where nw1 is the numerical value of the theoretical knowledge of the expert; nw2 is the numerical value of the assessment of the practical experience of the expert; nw3 is the numerical value of the expert's ability to predict. To determine the consistency of individual expert rankings, the multiple rank correlation coefficient was calculated:

$$
\mathrm{W}=(12 \mathrm{SD}) /(\mathrm{m} 2(\mathrm{n} 3-\mathrm{n}))
$$

Where $m$ is the number of signs; $n$ is the number of observations; SD-deviation of the sum of squares of ranks from the average of their squares. The presence of a tight connection between the attributes evaluated by experts was proved by checking the materiality of the relationship based on Pearson's consent criterion:

$$
\mathrm{X} 2=\mathrm{m}(\mathrm{n}-1) \mathrm{W} \leq \mathrm{X} 2 \operatorname{table}(\alpha, \mathrm{k})
$$

Where $\alpha$ is the level of the significance criterion;

$\mathrm{K}=\mathrm{n}-1$ - the number of degrees of freedom. The value of the coefficient of correlation (W) calculated by the formula (2) in the presented group was 0.87602 (maximum value 1.0 ). The value X2 calculated by the formula (3) corresponds to it criterion 154.2 (tabular value 23.7) at a 5\% level of the significance criterion and 14 degrees of freedom. The given values confirm the sufficient likelihood of a consistent opinion of experts and the validity of the use of an expert survey.

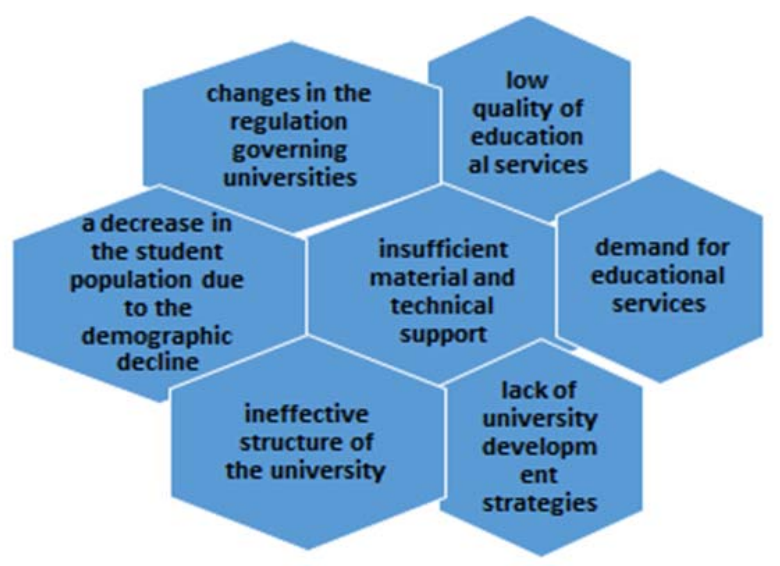

Figure 7. Risk-forming factors

The analysis of the results of the expert survey indicated that the most significant risk-forming factors are described in Figure 7.

This work substantiates the possibility of applying the method of expert assessments in the process of risk management in universities, not only for ranking factors affecting the degree of risk but also for determining the likelihood of risk situations. Using the procedure of probabilistic and statistical risk assessment (taking into account the opinions of experts) of the implementation of an innovative project at a university, the author argues that the use of quantitative estimates of the probability of exposure to factors will allow a more informed choice of innovative projects to finance and participate in the research teams of the university. This work examines the essence and content of risk management strategies in relation to the activities of higher education institutions and emphasizes the fact that the choice of risk management strategy is determined by the overall development strategy of the university, and the scientific, pedagogical and economic potential of the educational institution serves as the basis for its development and implementation. Under the conditions of market relations, the process of implementing risk management strategies should become part of managerial work along with the management of the educational process, research, finance, etc. Therefore, in this work, risk management in the activities of the university is considered as a set of methods for 
analyzing and neutralizing risk factors, combined into a system of planning, monitoring and corrective actions. This approach allowed this work to formulate and propose a risk management algorithm in Oman universities, presented in Figure 8. The algorithm developed by this work allows providing flexibility and adaptability of the risk management system in the activities of universities due to the fact that the results of each stage become data for subsequent stages, forming a decision-making system with feedback. Such a system ensures the most efficient achievement of risk management goals since the information obtained at each stage allows us to adjust not only the methods of influencing the risk but also the risk management goals themselves.

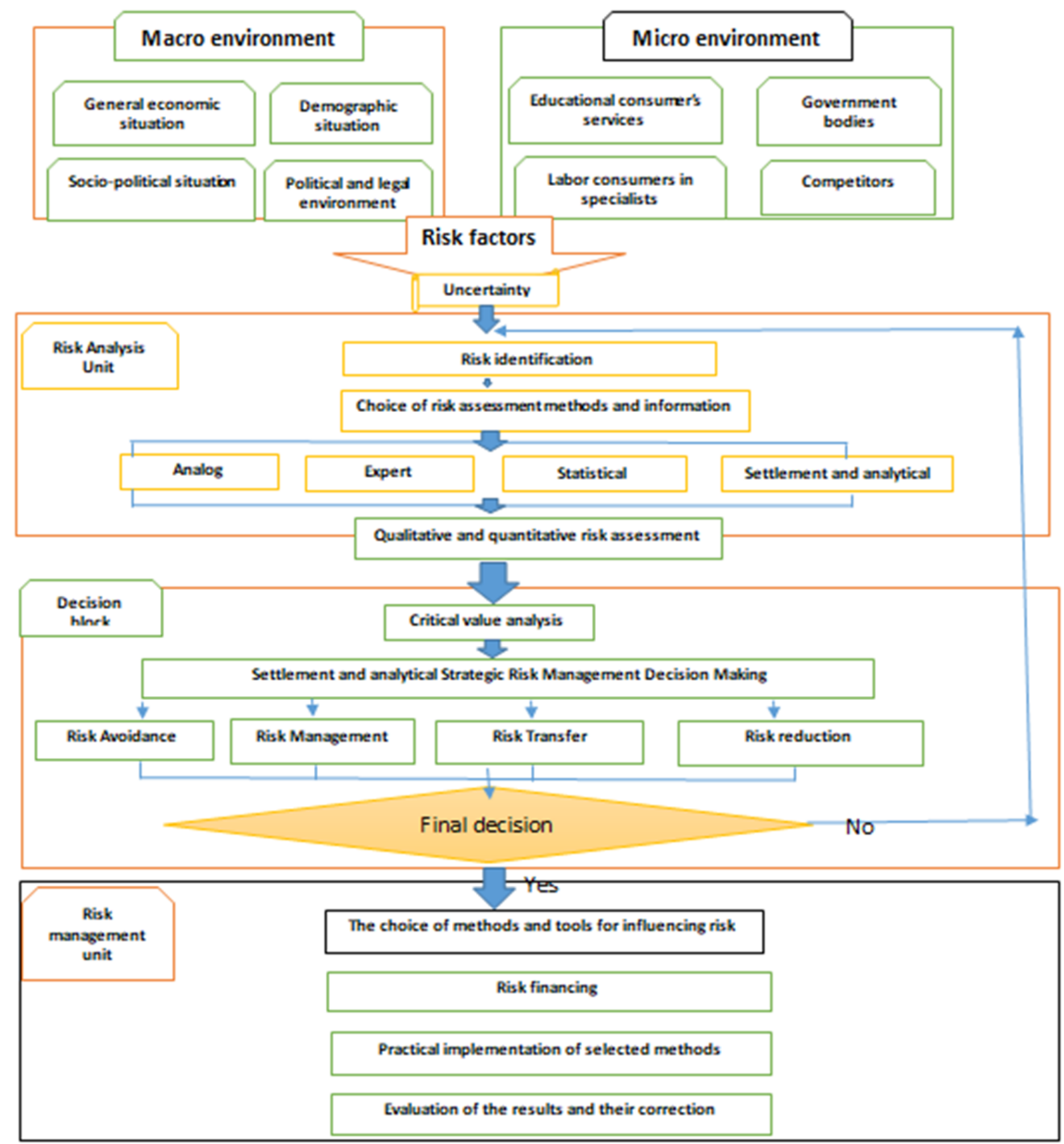

Figure 8. Algorithm of risk management in the activities of universities

The application of the risk management algorithm developed by this work will allow universities to, identify factors and sources of relevant and potential risks in its activities, obtain characteristics of the likelihood of the realization of a particular risk, as well as possible damage associated with undesirable developments, track risks at the stage of occurrence of a negative trend, develop, plan and, if necessary, implement measures to reduce risk. Finally, this work demonstrates the effectiveness score and the weighted score for each university unit alongside with the developed criteria's, before using the Proposed Risk Management algorithm as shown in Figure 9. and Figure 10. show the results after using the Proposed Risk Management algorithm. 


\begin{tabular}{|c|c|c|c|c|c|c|c|c|c|c|c|c|c|}
\hline \multicolumn{2}{|c|}{ Units Evaluation (University Rating) } & \multicolumn{2}{|c|}{ Unit1 } & \multicolumn{2}{|c|}{ Unit 2} & \multicolumn{2}{|c|}{ Unit 3} & \multicolumn{2}{|c|}{ Unit 4} & \multicolumn{2}{|c|}{ Unit 5} & \multicolumn{2}{|c|}{ Unit } \\
\hline Criteria & Highest Score & Score & Weighted score & Score & Weighted score & Score & Weighted score & Score & Weighted score & Score & Weighted score & Score & H \\
\hline Functionality & 2 & 1 & $11 \%$ & 1 & $13.2 \%$ & 2 & $18.3 \%$ & 2 & $15.0 \%$ & 2 & $15.0 \%$ & 1 & \\
\hline Ease of Use & 2 & 1 & $6.8 \%$ & 1 & $9.5 \%$ & 1 & $7.5 \%$ & 2 & $15.0 \%$ & 1 & $7.5 \%$ & 1 & \\
\hline Documentation & 2 & 1 & $2.3 \%$ & 1 & $1.8 \%$ & 1 & $2.9 \%$ & 1 & $1.3 \%$ & 1 & $2.5 \%$ & 1 & \\
\hline Availability & 2 & 1 & $5.7 \%$ & 1 & $7.1 \%$ & 2 & $8.3 \%$ & 1 & $5.0 \%$ & 2 & $7.5 \%$ & 1 & \\
\hline Response Time & 2 & 1 & $5.3 \%$ & 1 & $5.3 \%$ & 1 & $5.0 \%$ & 1 & $5.0 \%$ & 1 & $5.0 \%$ & 1 & \\
\hline Training & 2 & 2 & $4.4 \%$ & 2 & $4.5 \%$ & 2 & $4.6 \%$ & 1 & $2.5 \%$ & 2 & $5.0 \%$ & 2 & \\
\hline Reliability & 2 & 1 & $3.7 \%$ & 0 & $2.4 \%$ & 1 & $5.8 \%$ & 0 & $0.0 \%$ & 1 & $2.5 \%$ & 0 & \\
\hline Reporting & 2 & 1 & $3.8 \%$ & 2 & $7.9 \%$ & 2 & $9.2 \%$ & 1 & $5.0 \%$ & 1 & $2.5 \%$ & 1 & \\
\hline II support & 2 & 1 & $5.8 \%$ & 1 & $6.1 \%$ & 1 & $6.7 \%$ & 1 & $5.0 \%$ & 2 & $7.5 \%$ & 1 & \\
\hline
\end{tabular}

Figure 9. Rating results before using the Proposed Risk Management algorithm

\begin{tabular}{|c|c|c|c|c|c|c|c|c|c|c|c|c|c|}
\hline \multicolumn{2}{|c|}{ Units Evaluation (University Rating) } & \multicolumn{2}{|c|}{ Unit 1} & \multicolumn{2}{|c|}{ Unit 2} & \multicolumn{2}{|c|}{ Unit 3} & \multicolumn{2}{|c|}{ Unit 4} & \multicolumn{2}{|c|}{ Unit 5} & \multicolumn{2}{|c|}{ Unit } \\
\hline Zriteria & Highest Score & Score & Weighted score & Score & Weighted score & Score & Weighted score & Score & Weighted score & Score & Weighted score & Score & W \\
\hline unctionality & 3 & 5 & $33 \%$ & 5 & $33.3 \%$ & 4 & $26.7 \%$ & 2 & $10.0 \%$ & 6 & $40.0 \%$ & 3 & \\
\hline ase of Use & 2 & 6 & $45.0 \%$ & 4 & $30.0 \%$ & 6 & $45.0 \%$ & 5 & $37.5 \%$ & 3 & $22.5 \%$ & 6 & \\
\hline Jocumentation & 3 & 7 & $11.7 \%$ & 6 & $10.0 \%$ & 7 & $11.7 \%$ & 3 & $5.0 \%$ & 6 & $10.0 \%$ & 4 & \\
\hline tvailability & 2 & 5 & $25.0 \%$ & 7 & $35.0 \%$ & 5 & $25.0 \%$ & 8 & $40.0 \%$ & 5 & $25.0 \%$ & 7 & \\
\hline Response Time & 2 & 6 & $30.0 \%$ & 5 & $25.0 \%$ & 8 & $40.0 \%$ & 6 & $30.0 \%$ & 3 & $15.0 \%$ & 5 & \\
\hline Iraining & 2 & 4 & $10.0 \%$ & 8 & $20.0 \%$ & 3 & $7.5 \%$ & 4 & $10.0 \%$ & 7 & $17.5 \%$ & 3 & \\
\hline Reliability & 2 & 10 & $50.0 \%$ & 9 & $45.0 \%$ & 9 & $45.0 \%$ & 8 & $40.0 \%$ & 8 & $40.0 \%$ & 7 & \\
\hline Reporting & 2 & 10 & $50.0 \%$ & 6 & $30.0 \%$ & 7 & $35.0 \%$ & 9 & $45.0 \%$ & 4 & $20.0 \%$ & 8 & \\
\hline T support & 2 & 7 & $35.0 \%$ & 7 & $35.0 \%$ & 4 & $20.0 \%$ & 4 & $20.0 \%$ & 3 & $15.0 \%$ & 5 & \\
\hline
\end{tabular}

Figure 10. Rating results after using the Proposed Risk Management algorithm

Figure 11. summarizes the comparison results for rating the university risk management level, the current state and after applying the proposed solution. The proposed approach could improve risk management in education institutions by $24 \%$.

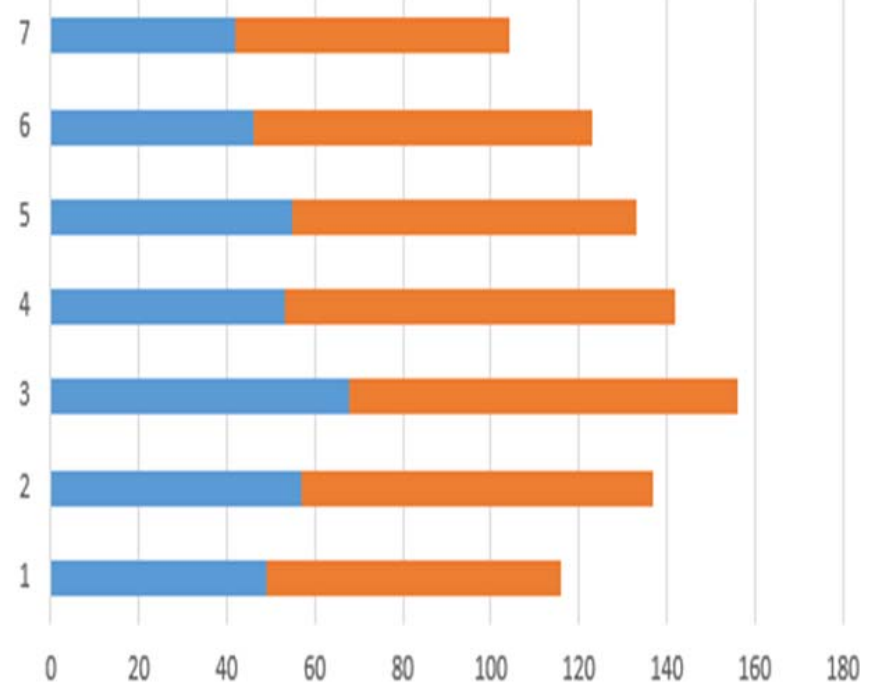

\section{Before After}

Figure 11. Comparison results for the proposed solution

In the final part of this work, out of the totality of risk management methods traditionally considered in risk management theory, Figure 12. singles out and classify those that can be used in the process of risk management in universities, taking into account the specifics of their activities.

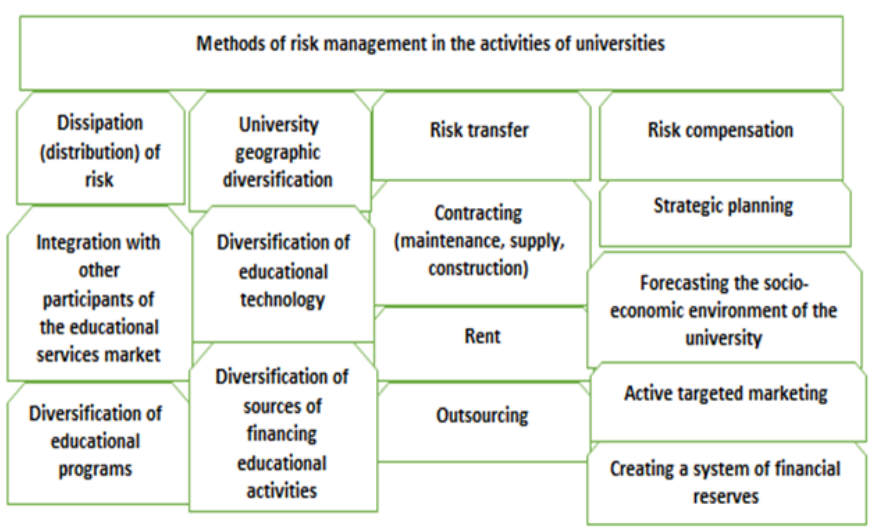

Figure 12. Classification of risk management methods in the activities of universities

This work has examined in detail the contents of each of the above methods, disclosed the advantages and disadvantages of their use in the activities of universities and proposed a set of scientific and methodological recommendations that allows to effectively use methods of risk neutralization in the risk management process of universities. The paper proposes to use the mechanism of vertical and horizontal integration of the university with other participants in the educational services market as a risk dissipation tool. The main objectives of horizontal integration will be to jointly solve problems in the field of educational services, rationalize the management of educational activities, optimize the use of resources (information, publishing, etc.). As an option of this kind of integration, inter-university activities can be considered for joint training of specialists, for students to master several related training programs, 
which can be organized in the form of associations, non-profit associations, and partnerships, educational consortia. Vertical integration is used to establish interaction and cooperation between the university and educational institutions of the previous levels of education, research institutes, enterprises, and government bodies interested in training highly qualified specialists. The diversification mechanism, as a way of risk distribution, can be implemented in the form of expanding the range of specialties and changing the structure of specialist training at the university (diversification of educational programs), developing new regional markets through the opening of branches and representative offices (geographical diversification of activities), using remote systems and technologies education (diversification of educational technologies). The application of this method will allow the university to maintain its potential (personnel, material and technical) and will help to increase its competitiveness in the educational services market in the context of a demographic decline and reform of financing mechanisms for higher education. Strategic planning, forecasting the socio-economic situation, reserving financial resources as tools for applying the risk compensation method will prevent the weakening of the university's position in the educational services market and timely develop a set of compensating measures. Figure 13. demonstrates samples of the developed risk logs for the finding risks at the University and identified who is affected and also shows the mechanisms and tools for risk reduction.

\begin{tabular}{|l|l|l|l|}
\hline Risk Description & When Changing staffing the reduction in the position of an employee \\
\hline Risk Category & \multicolumn{3}{|l|}{} \\
\hline Trigger (Event) & \multicolumn{2}{|l|}{} \\
\hline Risk rating & Very High (Rating +4 & Impact on quality & High \\
\cline { 3 - 4 } & & Impact on schedule & High \\
\cline { 3 - 4 } & & Impact on Cost & High \\
\hline Risk Handling Decision & Reduce Risk & Owner & \\
\hline Mitigation risk Plan & \multicolumn{3}{|l}{} \\
\hline Contingency Plan & \multicolumn{3}{|l}{} \\
\hline
\end{tabular}

Figure 13. Samples of Risk Management Log in education system

\section{Conclusions}

Higher education institutions are increasingly becoming subjects of the market, whose activities are largely determined by the level of supply and demand for educational services and evaluated in terms of economic performance criteria. The application of the risk management concept will provide the educational institution with the most effective solutions, in accordance with the requirements of the market and will allow timely response to changes in the external environment. The proposed typology of risk management concepts has made it possible to substantiate the possibility of applying the basic principles of business risk management in the risk management process of universities. The scientific approach to risk management requires its taxonomy. In this work, primary and secondary signs of the classification of risks arising in the activities of universities were highlighted. The significance of the study lies in the possibility of using the risk management concept by the university. In order to identify the real situation of a particular educational institution in the market, to objectively assess threats and opportunities, and to develop effective management decisions. An analysis of the content of modern risk management concepts by this work made it possible to construct a typology based on the definition of the nature of the risk category. The obtained results were based on analyzing the educational institutions activities of higher education. To explore the essence of the concept of risk in a theoretical aspect, taking into account the specifics of the functioning of higher education institutions; highlight and systematize the factors contributing to risks, assess the impact of these factors on risk management processes in universities; develop a risk management algorithm in the activities of universities; develop scientific and practical recommendations for risk management in University activities. The outcomes of this work conclude that, in implementing risk management strategies at universities, it is necessary to apply the risk management methods. Risk distribution, which involves the use of a diversification mechanism and sources of financing for the university, educational programs, educational technologies, geographical diversification of activities and risk transfer. 


\section{References}

[1]. Shannaq, B., Rafael, Y., \& Alexandro, V. (2010). Student relationship in higher education using data mining techniques. Global Journal of Computer Science and Technology.

[2]. Badran, A., \& Muwalla, M. (2019). Quality assurance and relevance for competitive higher education: Context of Jordan. In Major Challenges Facing Higher Education in the Arab World: Quality Assurance and Relevance (pp. 257-276). Springer, Cham.

[3]. Al-Azzawi, F., \& Shannaq, B. (2019). Fuzzy Analysis Model for Classifying Exams Questions. In Learning Quality Management System Based on Bloom's Taxonomy Verbs. (pp.69-79). AUS, Springer.

[4]. Loucks, N. \& Atallo, D. (2018). What Makes an ERM Leader in Higher Education. University risk management and insurance association journal.

[5]. El-Kogali, S. E. T., \& Krafft, C. (Eds.). (2019). Expectations and Aspirations: A New Framework for Education in the Middle East and North Africa. The World Bank.

[6]. Vasile, E., \& Croitoru, I. (2012). Integrated risk management system-key factor of the management system of the organization. risk management-Current issues and challenges, InTech, 253-284.

[7]. Krasnova, L. A., \& Shurygin, V. Y. (2017). Development Of teachers' Information Competency In Higher Education Institution. Astra Salvensis, (10).
[8]. Gallagher, A. (2009). Road to implementation: Enterprise risk management for colleges a universities. Higher Education Practice.

[9]. Spikin, I. C. (2013). Risk Management theory: the integrated perspective and its application in the public sector. Estado, Gobierno y Gestión Pública, (21), 89-126.

[10]. Ruzic-Dimitrijevic, L., \& Dakic, J. (2014). The risk management in higher education institutions. Online Journal of Applied Knowledge Management, 2(1), 137152.

[11]. Coopers, P. (2018). Managing Risk in Higher Education. Higher Education Sector Risk Profile.

[12]. Hsu, L., Fournier, S., \& Srinivasan, S. (2016). Brand architecture strategy and firm value: how leveraging, separating, and distancing the corporate brand affects risk and returns. Journal of the Academy of Marketing Science, 44(2), 261-280.

[13]. Shannaq, B. \& Al Shamsi I. (2019). Innovative Web Service for Streaming Student Tweeting in Real-Time Technology. International Journal of Innovative Technology and Exploring Engineering,9(2), 2278-3075.

[14]. Brossman, C. (2016). Building a travel risk management program: Traveler safety and duty of care for any organization. Butterworth-Heinemann.

[15]. Griffin, O. R. (2015). A View of Campus Safety Law in Higher Education and the Merits of Enterprise Risk Management. Wayne L. Rev., 61, 379. 